much less in size and cost, and in space occupied; than that necessary in any other system used in the manufacture of phenol, and doubtless this siatement applies with equal force to the manufacture of many other substances. Crude diphenyl ether, for example, was produced in the same manner and in almost the same time.

At the time of Aylsworth's death, development work on the production of phenol had not proceeded far enough to say with certainty what proportion the final product would bear to the materials used, but there is little waste involved, for the unreacted materials can be recovered and again passed through the apparatus, and their quantity controlled by the time they are under reacting conditions, and this in turn by the size of the apparatus and the proportionate time used.

Theoretically, one pound of benzene should produce one pound of phenol. Moreover, the salt required to prepare the electrolytic chlorine used in the reaction is again formed, and could be recovered. Possibly, also, the hydrogen used in the electrolytic process might be used to furnish part of the heat for the reaction. A Ioo per cent production, of course, is not possible, as there are unavoidable wastes in the electrolytic process and in the chlorination of the benzene, and also a very small loss in the conversion of chlorobenzene to phenol.

\section{COMPARISON OF METHODS}

Many methods of synthetic phenol manufacture have been developed: ${ }^{1}$ A brief description of one method is given herewith for comparison with the Aylsworth process.

The ordinary method is as follows:

I-A mixture of sulfuric acid and benzene is allowed to react for 18 or 20 hrs. Benzenesulfonic acid is formed to the extent of about 60 per cent of the sulfuric acid taken. By the addition of oleum, containing 25 per cent sulfuric anhydride, to the diluted acid, more benzene is sulfonated, giving a total efficiency of about 80 per cent of the total sulfuric acid.

2-The benzenesulfonic acid is separated from excess sulfuric acid by treatment with lime. After filtering from calcium sulfate, the calcium benzenesulfonate is converted into the sodium salt by treatment with sodium carbonate. A considerable loss of the sodium salt occurs in the removal of calcium carbonate in a filter press.

3-The sodium benzenesulfonate is next evaporated to dryness, usually with multiple-effect evaporators.

4-It is then converted to sodium phenylate by fusion with an excess (about 75 per cent) of the theoretical molecular proportions of caustic soda. This excess is generally wasted, though it can be recovered economically when caustic is high in price by an elaborate apparatus, as described further on.

5-The fused mass is entirely dissolved in water and the solution is neutralized with acid, and allowed to stand while the phenol separates out. The latter is drawn off and distilled, and the balance of the solution (containing some phenol) is thrown away, but the sulfite of soda may be recovered if desired. Losses occur in distillation.

The Aylsworth method consists of the following steps:

Met. Chem. Eng., 13 (1915), 686-690; 15 (1916), 185-192.
I-Chlorobenzene and caustic soda react to produce sodium phenylate and salt.

2-The sodium phenylate and salt are neutralized with hydrochloric acid and the crude phenol and salt solution allowed to separate by settling.

3-By blowing steam through the salt solution an additional quantity of phenol is recovered.

The difference in the two methods is evident at a glance and as each step is carried out in a different unit of apparatus, the smaller size of the plant as a whole in the case of the Aylsworth method is also apparent. Not only is there less apparatus, but in nearly each instance the units of the Aylsworth apparatus are smaller because of the greater rapidity with which the work is done, thus making possible important economies in time, labor, floor space, capital investment, etc.; a cheaper acid is used and only about 5 per cent of the quantity, and about 40 per cent of the amount of caustic soda.

\section{AN ELECTRIC HEATER FOR THE COAL-TAR NAPHTHA DISTILLATION TEST}

By J. Bennett Hill and Richard B. Chillas

\author{
H. W. Jayne Laboratory, The Barrett Co., Frankford, \\ PaIIADELPHIA, PA. \\ Received October 29, 1919
}

The control of the plant operation of fractional distillation processes, particularly in the distillation of coal-tar naphthas, is generally carried out by observing the distillation range of samples of the distillate taken as it runs off the still. For this purpose the commonly used method is the distillation test, somewhat similar to the petroleum distillation method, and recently fully described by Weiss. ${ }^{1}$ On account of the fact that this method requires the use of a gas flame, which in a benzol plant would be out of the question on account of the fire risk, it is necessary to send the samples to the laboratory to be tested. It would generally be not only much more convenient but also more economical to have them made on the spot. In order to avoid the risk of the flame, we have used a steam heater to a considerable extent in our benzol plant in carrying out the distillation tests. This device was, however, open to two objections: first, that the heating conditions of the flask were so decidedly different from those obtained with gas heating that the results were different, and, second, that only low boiling liquids could be tested. This paper describes an electric heating method which eliminates the fire risk and at the same time gives results identical with those obtained in the laboratory, using a gas flame.

Another type of electrical heater for distillation tests has recently been developed by the Bureau of Mines, ${ }^{2}$ the idea of this being, however, to provide a cleaner and more nearly uniform heat rather than to cut down fire risk. A heater such as this with exposed hot wires could not be used in a building where inflammable vapors are present.

The heater selected for this work was an electrically

1 This Journal, 10 (1918), 1006.

E. W. Dean, Ibid., 10 (1918), 823. 


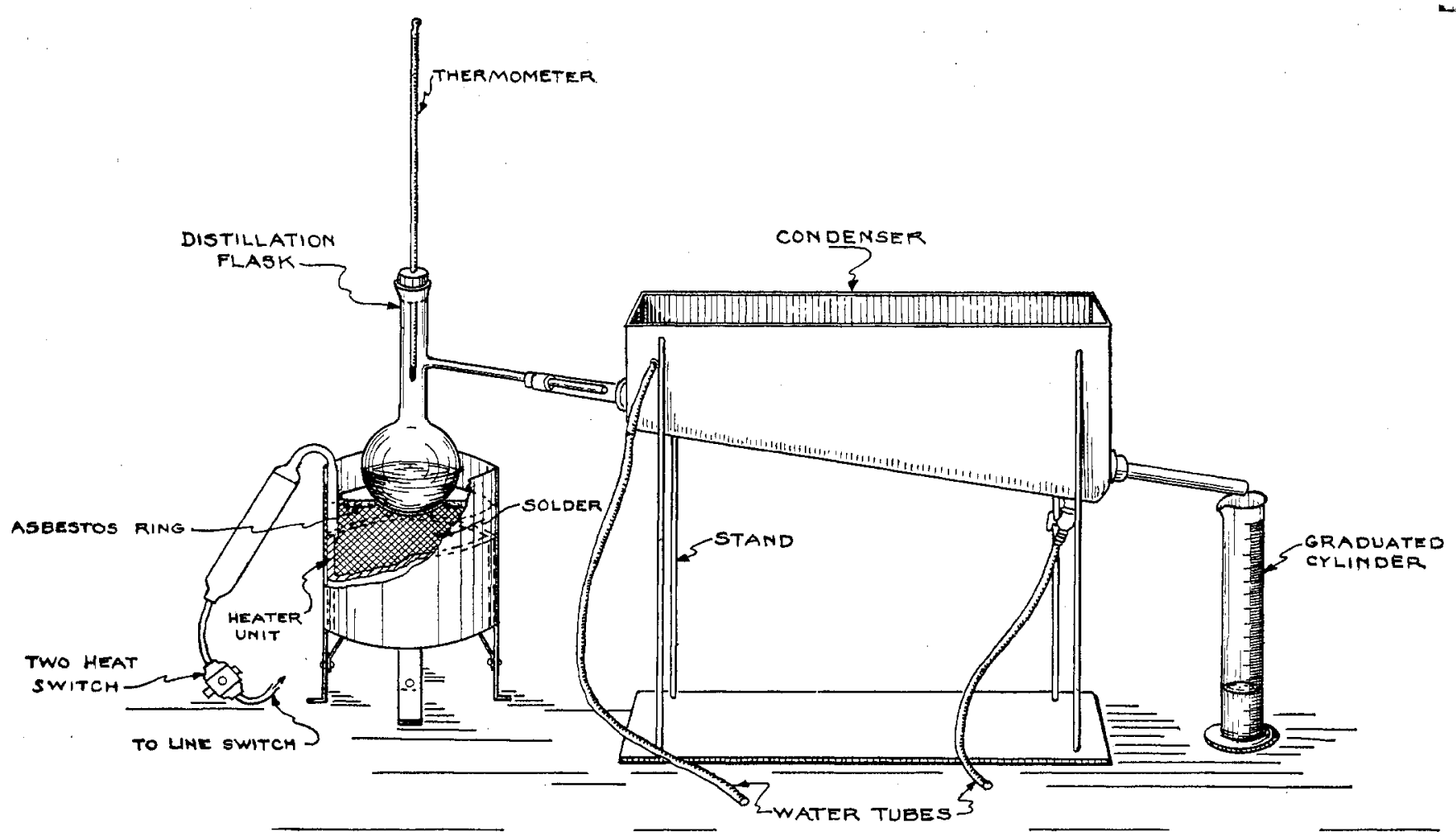

heated solder pot such as is on the market. ${ }^{1}$ It consists of a cylindrical iron pot, $\mathrm{I} 2.5 \mathrm{~cm}$. in diameter and $10 \mathrm{~cm}$. in height, with a heating unit suitably and completely enclosed, and entirely immersed, when in use, in the solder. The heating unit, cylindrical in form, $5.5 \mathrm{~cm}$. in height, $10.5 \mathrm{~cm}$. inside diameter, and approximately $7 \mathrm{~mm}$. in thickness, rests on the bottom of the pot and is set slightly away from the wall in such a manner as to be completely surrounded by the solder. The pot is filled to within $3 \mathrm{~cm}$. of the top by approximately $\mathrm{I}_{5} \mathrm{lbs}$. of 50 per cent lead50 per cent tin solder. A heater appropriate to the lighting circuit voltage is used and by means of a switch the current can be varied between a low heat taking 400 watts, which will hold the temperature of the bath between $240^{\circ}$ and $280^{\circ} \mathrm{C}$, and a high heat taking 800 watts, which will hold the bath at a temperature of $345^{\circ}$ to $380^{\circ} \mathrm{C}$. With this device no part of the apparatus with a temperature higher than the solder itself is exposed to outside vapors.

Safety tests have been made by pouring benzene into the solder bath at both the low and high heats. No cases of ignition of the material have been obtained.

The general arrangement of the apparatus for the test is shown in the figure. A ring of asbestos board cut to fit the bath is floated on the surface of the solder and the heat supplied to the flask is regulated by the size of the circular hole in this pad and by the depth to which the flask is immersed in the molten metal. In practice the bath is always kept hot, the high or low heats being used according to the general class of substances to be tested, the low heat being sufficient for materials boiling up to about $180^{\circ} \mathrm{C}$. To conduct

1 Made by the Westinghouse Electric and Manufacturing Co. the test the proper asbestos pad is floated on the solder, the sample of liquid introduced into the flask, the flask connected with the condenser apparatus and dipped into the molten metal through the hole in the pad. The rate of distillation can readily be adjusted to correspond to that obtained with the gas flame method.

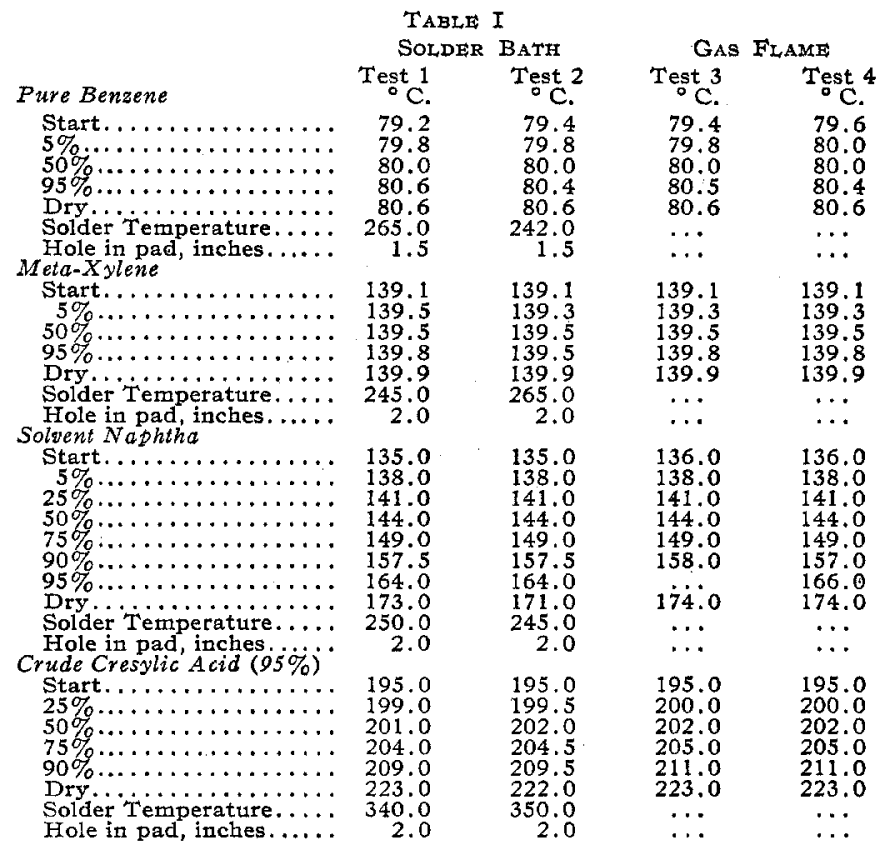

A series of comparisons has been made of boiling ranges obtained by this method and those obtained by the standard gas flame distillation. These results, a few of which are shown in Table I, are practically identical. 